\title{
Reliability Analysis on Ultimate Uplift Capacity of Digged Foundation in Transmission Line \\ Dongxue Hao ${ }^{1,}$, Xin Dai ${ }^{1, b}$ and Rong Chen ${ }^{1, c}$
}

\author{
${ }^{1}$ School of Civil Engineering and Architecture, Northeast Dianli University, Jilin, 132012, China \\ ahaodongxue2005@126.com, bzichuanyixuan@163.com, 'Ig1316cih@126.com
}

Keywords: Reliability index, Digged foundation, Uplift capacity, Gravel soil.

\begin{abstract}
Reliability analysis of uplift stability based on the first order second order method for digged foundation in gravel soil has been made by non-dimensionalization for ultimate state equation and combining with the test results. The ratio of test value to calculated uplift capacity $K_{\mathrm{p}}$ that reflects the uncertainty of calculation model obeys normal distribution via single sample K-S test. When the ratio $\rho$ of variable and permanent loads is certain, reliability index $\beta$ increases linearly with safety factor $K$. For given value of $K$, reliability index $\beta$ change slightly with $\rho$. For digged foundations in gravel soils, the reliability index $\beta$ ranges from 2.74 to 3.22 when $K=2.5-4.0$.
\end{abstract}

\section{Introduction}

Gobi desert is widely distributed in the northwest of China, which is the terrain with coarse sand and gravel overlying the hard soil layer. With the development of power grid construction, more and more transmission lines need to go through the Gobi desert area. The cost, time and labor for transmission tower foundation construction account for a large proportion in the whole project [1]. The uplift resistance of the foundations under normal circumstances is the design control conditions. It is effective to reduce the project cost and improve the level of environmental protection when suitable foundation type is selected. Foundation hole is digged by manual work in mountain area and it is actually rigid enlarged pile. This kind of foundation can provide good uplift capacity because soil structure and strength cannot be disturbed. The estimation of its uplift capacity is based on limited equilibrium method, consisting of vertical component of shear strength along failure surface, self-weight of soil within failure surface and self-weight of foundation. Technical code for design of foundation of overhead transmission lines (DL/T 5219-2014) [2] presented formula of uplift capacity. Luxian Long et al. [3, 4] performed reliability analysis using formula of uplift capacity in last version of design code (DL/T 5219-2005). And the reliability analysis of digged foundation should be performed based on updated formula. It is necessary to carry out reliability-based design for foundation in transmission line to coincide with superstructure design theory $[5,6]$.

Therefore, this paper established uplift ultimate limit state equation of diggged foundation using shear method's formula provided in new design code. The distributions and statistical parameters of variables in state equation were determined by combining with uplift test results of digged foundations. Reliability index is calculated by using "the first order second order method (JC)". The relationship of reliability level and frequently-used safety factor is established, which can provide reference reliability-based design.

\section{The Formula of Uplift Capacity}

Shear method is proposed in design code [2], and the calculation model is shown in Fig. 1. Calculation formula of uplift capacity $T_{\mathrm{uk}}$ for digged foundation is expressed as

For $h_{\mathrm{t}} \leq h_{\mathrm{c}}$

$$
T_{\mathrm{uk}}=\frac{A_{1} c h_{t}^{2}+A_{2} \gamma_{s} h_{t}^{3}+\gamma_{s}\left(A_{3} h_{t}^{3}-V_{0}\right)}{2.0}+G_{f}
$$


For $h_{\mathrm{t}} \geq h_{\mathrm{c}}$

$$
T_{\mathrm{uk}}=\frac{A_{1} c h_{c}^{2}+A_{2} \gamma_{s} h_{t}^{3}+\gamma_{s}\left(A_{3} h_{c}^{3}+\Delta V-V_{0}\right)}{2.0}+G_{f}
$$

where $c$ is soil cohesion; $h_{\mathrm{t}}$ is embedment depth; $h_{\mathrm{c}}$ is critical embedment depth; $A_{1}, A_{2}, A_{3}$ are non-dimensional coefficients determined by friction angle $\varphi$ and $\lambda\left(\lambda=h_{\mathrm{t}} / D\right) ; D$ is diameter of foundation base; $\Delta V$ is the volume of cylinder of depth $\left(h_{\mathrm{t}}-h_{\mathrm{c}}\right) . V_{0}$ is the volume of foundation; $G_{\mathrm{f}}$ is self-weight of foundation.
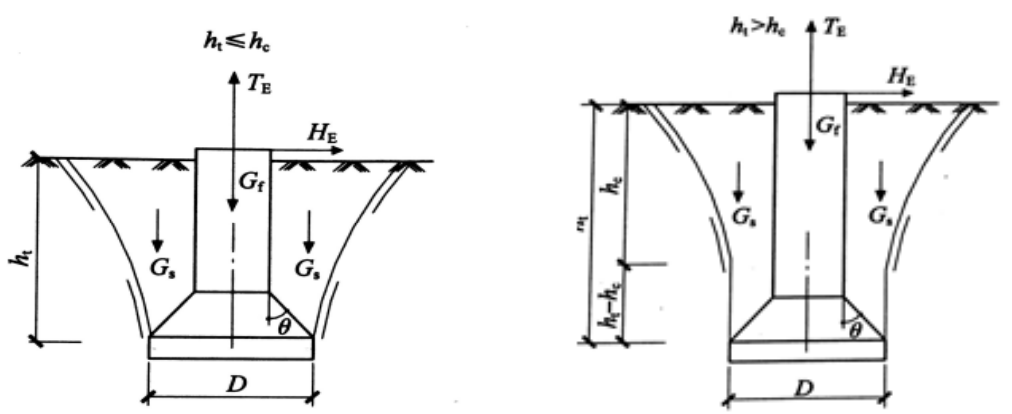

Fig. 1 Calculation model of uplift capacity.

\section{Limit State Equation}

Working state equation of uplift stability of digged foundation can be expressed as Eq. (2), where $S$ and $\mathrm{R}$ represent action effects and resistance respectively.

$$
\mathrm{Z}=\mathrm{R}-\mathrm{S}
$$

With the changes in $\mathrm{R}$ and $\mathrm{S}$, the performance function $Z$ has three states: When $\mathrm{Z}<0$, the structure is in a failure state; if $Z>0$, it means that the structure is in the reliable state; when $Z=0$, it means that the structure in the limit state.

The load acting on the transmission line tower structure can be divided into dead load, live load and special load. Special load such as earthquake and conductor break is not considered here. Thus state equation comprises three basic random variables: uplift resistance, dead load effects and live load effects. Then Eq. (2) can be rewritten as Eq. (3).

$$
\mathrm{g}(\mathrm{T}, \mathrm{G}, \mathrm{Q})=\mathrm{T}-\mathrm{G}-\mathrm{Q}=0
$$

where $T, G$ and $Q$ represent the uplift capacity of foundation, the design dead load effects and the design live load effects respectively.

If the probability distributions for three basic random variables can be obtained, the reliability analysis can be made by JC method.

According to the deterministic method [7], standard values of three basic random variables $T_{\mathrm{uk}}, G_{\mathrm{k}}$ and $Q_{\mathrm{k}}$ yield the following relationship.

$$
\mathrm{Tuk}=\mathrm{K}(\mathrm{Gk}+\mathrm{Qk})=\mathrm{K}(1+\rho) \mathrm{Gk}
$$

where $T_{\mathrm{uk}}$ is calculated value of uplift capacity; $G_{\mathrm{k}}, Q_{\mathrm{k}}$ is the standard value of the dead load and live load effects respectively, determined according to the load code; $K$ is safety factor, in foundation engineering, $K$ is generally taken as 2.5-4.0; $\rho=$ the values of the live load effect to dead load effect ratio $\left(Q_{\mathrm{k}} / Q_{\mathrm{k}}\right)$.

Substituting Eq. (4) into (3) and both sides of equation divided by $T_{\mathrm{uk}}$ and, we can get

$$
\frac{T}{T_{\mathrm{uk}}}-\frac{1}{K(1+\rho)} \frac{G}{G_{\mathrm{K}}}-\frac{\rho}{K(1+\rho)} \frac{Q}{Q_{\mathrm{K}}}=0
$$

$T / T_{\mathrm{uk}}, G / G_{\mathrm{K}}$ and $Q / Q_{\mathrm{K}}$ are defined as $K_{\mathrm{p}}, K_{\mathrm{G}}$ and $K_{\mathrm{Q}}$ respectively, then Eq. (5) is written as, 


$$
K_{\mathrm{p}}-\frac{1}{K(1+\rho)} K_{\mathrm{G}}-\frac{\rho}{K(1+\rho)} K_{\mathrm{Q}}=0
$$

Actually, Eq. (6) with non-dimensional variables is equivalent to limit state Eq. (3). This will make the calculation of reliability index $\beta$ greatly simplified. $\beta$ only relates to the statistical characteristics of random variables $K_{\mathrm{p}}, K_{\mathrm{G}}, K_{\mathrm{Q}}$, the values of the live load effects to dead load effect ratio $\rho$ and safety factor $K$.

\section{Statistical Analysis of the Basic Variables}

The Statistical Analysis of Load. Load types applied on tower foundation and their statistical parameters accord to transmission tower. For simplicity, statistical characteristics of $K_{\mathrm{G}}=G / G_{\mathrm{k}}$ in "load code for design of building structures" is adopted [7]. $K_{\mathrm{G}}$ obeys normal distribution with mean $\mu_{\mathrm{KG}}=1.06$, variance $\sigma_{\mathrm{KG}}=0.074$. By $\chi^{2}$ or K-S inspection, when significance level is 0.05 .

Based on load code [7], the probability distribution of the maximum wind pressure value is regarded as GUMBEL I by statistical analysis at the confidence level of 5\% for a group of representative wind data from meteorological station throughout the country. The statistical parameters of random variable $K_{\mathrm{Q}}$ are that $\mu_{\mathrm{KQ}}=0.998$ and $\sigma_{\mathrm{KQ}}=0.193$ in terms of a great deal of research data of wind load for transmission towers in the world.

\section{The Load Effects Ratio $\rho$}

Wind load is the main control factor in many live loads, hence this analysis consider wind load merely. A large amount of statistical results show that the ratio of wind load effect and dead load effect $\rho$ is between $0 \sim 9$. $\rho$ is taken as $0.5,1,2,2.5,1.5,3,3.5,4.0,4.5,5.0,5.5,6.0,6.5,7.0,7.5,8.0$, 8.5 and 9 in this analysis.

\section{Statistical Analysis of Non-Dimensional Uplift Capacity $K p$}

Table 1 shows the calculated value $T_{\mathrm{uk}}$ and measured values $T$ of uplift capacity. $K_{\mathrm{p}}$ is also calculated, which reflect the uncertainty of calculation model and parameter. Probability distribution of $K_{\mathrm{p}}$ satisfies normal distribution by K-S hypothesis test under the condition of $5 \%$ confidence level, shown in Fig. 2. The mean and variance of $K_{\mathrm{p}}$ are 1.309 and 0.251 respectively.

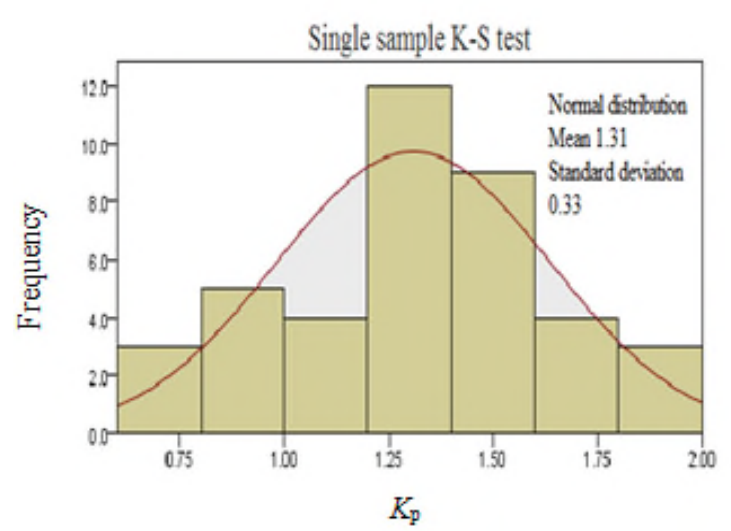

Fig. 2 Distribution of $K_{\mathrm{p}}$.

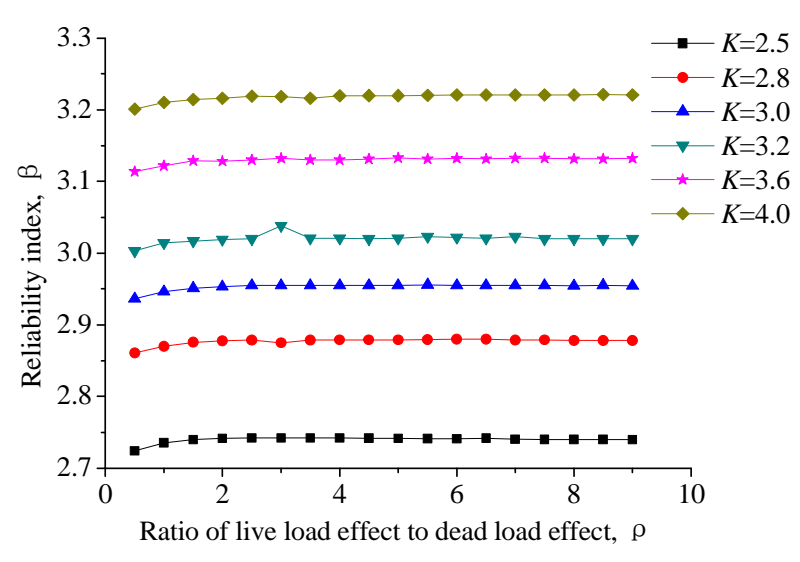

Fig. 3 Reliability index $\beta$ for foundation. 


\section{The Reliability Index}

Table. 1 The theoretical and test results of uplift capacity of foundation in Gobi gravel soil and value of $\mathrm{K}_{\mathrm{p}}$.

\begin{tabular}{|c|c|c|c|c|c|c|c|c|c|c|c|}
\hline No. & $h_{\mathrm{t}} / \mathrm{m}$ & $D / \mathrm{m}$ & $c / \mathrm{kPa}$ & $\varphi\left({ }^{\circ}\right)$ & $\begin{array}{c}\gamma_{\mathrm{s}} \\
/ \mathrm{kN} \cdot \mathrm{m}^{3}\end{array}$ & $\mathrm{~A}_{1}$ & $\mathrm{~A}_{2}$ & $\mathrm{~A}_{3}$ & $\begin{array}{l}\text { Test } \\
T / \mathrm{kN}\end{array}$ & $\begin{array}{c}\text { Cal } \\
T_{\mathrm{uk}} / \mathrm{kN}\end{array}$ & $K_{\mathrm{p}}$ \\
\hline 1 & 1.52 & 1.01 & 10.5 & 41.4 & 20.1 & 3.290 & 0.965 & 1.322 & 442.9 & 246.5 & 1.797 \\
\hline 2 & 2.46 & 1.64 & 10.5 & 41.4 & 20.1 & 290 & 0.965 & 1.322 & 1287.9 & 912.6 & 1.411 \\
\hline 3 & 3.44 & 2.29 & 10.5 & 41.4 & 20.1 & 3.290 & 0.965 & 1.322 & 2787.9 & 2277.8 & 1.224 \\
\hline 4 & 3.53 & 1.41 & 10.5 & 41.4 & 20.1 & 2.220 & 0.590 & 0.686 & 2235.4 & 1446.3 & 1.546 \\
\hline 5 & 5.09 & 2.04 & 10.5 & 41.4 & 20.1 & 2.220 & 0.590 & 0.686 & 5377.8 & 4056.6 & 1.326 \\
\hline 6 & 3.73 & 1.49 & 10.5 & 41.4 & 20.1 & 2.220 & 0.590 & 0.686 & 2021.3 & 1667.7 & 1.212 \\
\hline 7 & 6.34 & 1.81 & 10.5 & 41.4 & 20.1 & 1.851 & 0.458 & 0.496 & 6233.4 & 5755.8 & 1.083 \\
\hline 8 & 4.33 & 1.24 & 10.5 & 41.4 & 20.1 & 1.851 & 0.458 & 0.496 & 3425.1 & 1936.2 & 1.769 \\
\hline 9 & 6.62 & 1.89 & 10.5 & 41.4 & 20.1 & 1.851 & 0.458 & 0.496 & 5103.4 & 6539.3 & 0.780 \\
\hline 10 & 1.52 & 1.01 & 23.0 & 43.3 & 21.0 & 3.196 & 0.987 & 1.343 & 345.8 & 346.2 & 0.999 \\
\hline 11 & 2.46 & 1.64 & 23.0 & 43.3 & 21.0 & 3.196 & 0.987 & 1.343 & 1042.6 & 1137.6 & 0.916 \\
\hline 12 & 3.44 & 2.29 & 23.0 & 43.3 & 21.0 & 3.196 & 0.987 & 1.343 & 3591.4 & 2853.1 & 1.259 \\
\hline 13 & 3.53 & 1.41 & 23.0 & 43.3 & 21.0 & 2.157 & 0.601 & 0.697 & 2254.9 & 1831.2 & 1.231 \\
\hline 14 & 3.73 & 1.49 & 23.0 & 43.3 & 21.0 & 2.157 & 0.601 & 0.697 & 2678.2 & 2149.7 & 1.246 \\
\hline 15 & 6.34 & 1.81 & 23.0 & 43.3 & 21.0 & 2.157 & 0.601 & 0.697 & 7132.0 & 6884.0 & 1.036 \\
\hline 16 & 4.33 & 1.24 & 23.0 & 43.3 & 21.0 & & 0.467 & 0.505 & 3109.6 & 2446.0 & 1.271 \\
\hline 17 & 1.52 & 1.01 & 14.7 & 44.2 & 21.4 & 3.320 & 0.998 & 1.353 & 555.0 & 293.7 & 1.890 \\
\hline 18 & 2.46 & 1.64 & 14.7 & 44.2 & 21.4 & 3.320 & 0.998 & 1.353 & 1650.0 & 1059.8 & 1.557 \\
\hline 19 & 3.44 & 2.29 & 14.7 & 44.2 & 21.4 & 3.320 & 0.998 & 1.353 & 4471.2 & 2664.3 & 1.678 \\
\hline 20 & 3.53 & 1.41 & 14.7 & 44.2 & 21.4 & 2.130 & 0.607 & 0.703 & 3103.9 & 1645.6 & 1.886 \\
\hline 21 & 5.09 & 2.04 & 14.7 & 44.2 & & & 0.607 & & & & 1.288 \\
\hline 22 & 3.73 & 1.49 & 14.7 & 44.2 & 21.4 & 2.130 & 0.607 & 0.703 & 3135.7 & & 1.650 \\
\hline 23 & 1.85 & 1.20 & 19.0 & 40.0 & 20.0 & 3.300 & 0.929 & 1.272 & 598.5 & 499.8 & 1.197 \\
\hline 24 & 2.40 & 1.23 & 19.0 & 40.0 & 20.0 & 2.714 & 0.731 & 0.923 & 1131.7 & 763.6 & 1.482 \\
\hline 25 & 3.35 & 1.20 & 19.0 & 40.0 & 20.0 & 2.133 & 0.535 & 0.608 & 1930.9 & 1326.0 & 1.456 \\
\hline 26 & 3.00 & 1.40 & 19.0 & 40.0 & 20.0 & 2.538 & 0.672 & 0.823 & 1829.8 & 1259.5 & 1.453 \\
\hline 27 & 4.55 & 1.60 & 19.0 & 40.0 & & & 0.529 & 0.599 & & & 1.467 \\
\hline 28 & 3.88 & 1.80 & 19.0 & 40.0 & 20.0 & 2.523 & 0.667 & 0.815 & 3278.2 & 2486.4 & 1.318 \\
\hline 29 & 4.60 & 1.85 & 19.0 & 40.0 & 20.0 & 2.270 & 0.581 & 0.677 & 4233.7 & 3404.4 & 1.244 \\
\hline 30 & 2.30 & 1.64 & 15.6 & 42.1 & 20.9 & 3.630 & 1.108 & 1.580 & 669.6 & 993.9 & 0.674 \\
\hline 31 & 4.73 & 1.36 & 15.6 & 42.1 & 20.9 & 1.838 & 0.461 & 0.499 & 1705.5 & 2779.1 & 0.614 \\
\hline 32 & 1.66 & 1.10 & 16.5 & 43.6 & 21.3 & 3.180 & 0.990 & 1.346 & 753.5 & 377.1 & 1.998 \\
\hline 33 & 2.30 & 1.53 & 16.5 & 43.6 & 21.3 & 3.180 & 0.990 & 1.346 & 868.6 & 893.4 & 0.972 \\
\hline 34 & 3.27 & 2.30 & 16.5 & 43.6 & 21.3 & 3.480 & 1.102 & 1.550 & 2377.3 & 2610.3 & 0.911 \\
\hline 35 & 3.26 & 1.34 & 16.5 & 43.6 & 21.3 & 2.200 & 0.620 & 0.728 & 1848.2 & 1395.1 & 1.325 \\
\hline 36 & 4.12 & 1.65 & 16.5 & 43.6 & 21.3 & 2.147 & 0.603 & 0.699 & 3037.8 & 2567.3 & 1.183 \\
\hline 37 & 4.54 & 1.20 & 16.5 & 43.6 & 21.3 & 1.730 & 0.447 & 0.478 & 3050.1 & 2445.1 & 1.247 \\
\hline 38 & 5.32 & 1.50 & 16.5 & 43.6 & 21.3 & 1.790 & 0.468 & 0.506 & 5922.3 & 3994.0 & 1.483 \\
\hline 39 & 4.77 & 1.35 & 16.5 & 43.6 & 21.3 & 1.790 & 0.468 & 0.506 & 4167.4 & 2937.4 & 1.419 \\
\hline 40 & 3.48 & 1.74 & 20.1 & 40.6 & 21.1 & 2.618 & 0.712 & 0.885 & 1797.5 & 2080.6 & 0.864 \\
\hline
\end{tabular}


The reliability index can be calculated by JC method for various load ratio $\rho$ and safety factor $K$. The results of reliability index are plotted in Fig. 3. When load ratio $\rho$ is certain, reliability index $\beta$ increases with safety factor $K$. For given value of $K$, reliability index $\beta$ change slightly with $\rho$.

The load ratio $\rho$ ranges from 3.3 to 8.3 commonly. Therefore, the values of reliability index are averaged in the range of $\rho$ for various safety factors, listed in Table 2, which can provide reference for reliability-based design.

Table 2. Reliability index for various safety factors.

\begin{tabular}{|c|c|c|c|c|c|c|}
\hline Safety factor & 2.5 & 2.8 & 3.0 & 3.2 & 3.6 & 4.0 \\
\hline Reliability index(mean value) & 2.741 & 2.879 & 2.955 & 3.023 & 3.132 & 3.220 \\
\hline
\end{tabular}

\section{Conclusion}

Reliability analysis of uplift stability based on JC method for digged foundation in Gobi gravel soil has been made by non-dimensionalization for ultimate state equation and combining with the test results. The main conclusions are as follows: (1) The ratio of test value to calculated uplift capacity $K_{\mathrm{p}}$ that reflects the uncertainty of calculation model obey normal distribution with mean value of 1.309 and variance of 0.251 . This indicates that formula of the ultimate uplift capacity of digged foundation in design code will underestimate the uplift capacity. It is safe for project. (2) When the ratio $\rho$ of the variable load effect and permanent load effect is certain, reliability index $\beta$ increases with safety factor $K$. And reliability index $\beta$ changes slightly with the ratio $\rho$ for a given safety factor. For gobi gravel soils, when $K=2.5-4.0$, the reliability index $\beta$ ranges from 2.741 to 3.220. (3) Sufficient test data and accuracy of theoretical calculation are beneficial to improve the results of reliability analysis. This study can provide a reference to the reliability calibration analysis of uplift stability.

\section{Acknowledgement}

In this paper, the research was sponsored by the National Natural Science Foundation of China (Project No. 51308095, 51409045) and Natural Science Foundation of Jilin Province (Project No. 20130522068JH).

\section{References}

[1] X. L. Lu, Z. Z. Qian, R. M. Tong and W. F. Zheng, Field Test Analysis on Belled Pier Foundations under Tensile Lord in Gravel Gobi. J. Civil, Archit. Environ. Eng. 34(4) (2012) 24-30.

[2] DL/T 5219-2014. Technical code for design of foundation of overhead transmission line. Electric power industry standard of the People's Republic of China. (in Chinese)

[3] X. L. Lu, Reliability Analysis on Ultimate Uplift Bearing Capacity of Belled Pier Foundation in Transmission Line Engineering. Power Syst. Clean Energy, 28(1) (2012) 9-16. (in Chinese)

[4] B. Xu, E. X. Zeng, Y. Z. Bao, Y. W. Feng, Credibility Adjusting Analysis of Cut Method Resistance Drawing Design of Original State Earth Foundation. Electr. Power Surv. Des. 28(3) (2014) 58-67. (in Chinese)

[5] X. D. Fu and Z. D. Liu, Reliability analysis for vertical bearing capacity of shallow foundations. Rock Soil Mech. 21(4) (2000) 354-359. (in Chinese)

[6] K. K. Phoon, F. H. Kulhawy, M. D. Grigoriu, Reliability based design of foundations for transmission line structures, 1995, Report TR-105000. Palo Alto, CA: Electric Power Research Institute.

[7] GB50009-2012.Load code for design of building structures. National Standards of the People's Republic of China. (in Chinese) 